\title{
Accidental injuries in the Pediatric Emergency Department
}

\author{
Sarath Parambil Sasidhara Kurup, Swathi Padankatti ${ }^{*}$, Kuruvilla Thomas \\ From International Summit on Emergency Medicine and Trauma 2014 \\ Puducherry, India. 12-16 February 2014
}

\section{Objective}

To study the spectrum of accidental injuries in the Pediatric Emergency Department of a community hospital.

\section{Methods}

Setting: Pediatric Emergency Department (ED) of a Community hospital with around 10500 ED visits annually. The hospital conducts DNB Pediatrics, MCEM and BSc Accident \& Emergency Technology Courses.

Participants: 784 Children with accidental injuries between 0 and 18 years of age who attended ED in a 10-month period from January 2013 to October 2013. Design: Retrospective observational study.

Tools: The ED records of the study group were analysed retrospectively.

\section{Results}

Of a total of 8855 children seen in the ED during the study period, $784(8.9 \%)$ presented with accidental injuries. The age distribution was 48 (6.1\%), 345 (44\%), 172 (21.93\%), 131 (16.71\%), 88 (11.2\%), in <1 year, $1-5$ years, $5-10$ years, $10-15$ years and $15-18$ years age groups respectively. Falls accounted for $492(62.8 \%)$, cut injuries 76 (9.7\%), RTA 60 (7.7\%), poisoning $48(6.1 \%)$, sports related injuries 39 (4.97\%), burns 32 (4.1\%), crush injuries $15(1.91 \%)$, foreign body $12(1.53 \%)$, fight with peers 8 (1.02\%), child abuse $2(0.25 \%)$.

In $495(63.1 \%)$ males, falls accounted for 307 (62.4\% of total), cut injury 56 (73.7\%), RTA 37 (61.7\%), poisoning $25(52.1 \%)$, sports related injuries $28(71.8 \%)$ burns 18 (56.3\%), crush injuries 7 (46.7\%), foreign body 7 (58.3\%), fight with peers 8 (100\%), child abuse $2(100 \%)$.

Majority of accidents occurred in evening hours (290, $36.9 \%)$ and at home $(457,58.2 \%)$. Of 552 falls and
RTAs, 115 (20.8\%) and 86 (15.6\%) sustained head injury and extremity fracture respectively; $3(2.6 \%)$ and 18 (21\%) required immediate surgical intervention and open reduction respectively.

$232(29.6 \%)$ cases required hospitalisation. There was one death (a 15-year old girl who fell from terrace). Falls were the major cause of injury irrespective of age and gender.

\section{Limitations}

A longer study period could have perhaps yielded a larger spectrum of injuries.

\section{Conclusion}

Childhood accidental injuries can cause serious morbidity and mortality. Injuries peaked in the 1-5 years age group with falls being the leading cause of injury. Studying epidemiology of childhood injuries can help formulate effective preventive strategies and increase parental awareness.

Published: 25 July 2014

doi:10.1186/1865-1380-7-S1-P9

Cite this article as: Kurup et al: Accidental injuries in the Pediatric

Emergency Department. International Journal of Emergency Medicine 2014 7(Suppl 1):P9. 